\title{
Systematic review on mobile collaborative learning for engineering education
}

\author{
Anuradha Peramunugamage ${ }^{1}$ (C) Uditha W. Ratnayake ${ }^{1}$. \\ Shironica P. Karunanayaka ${ }^{2}$
}

Received: 18 December 2021 / Revised: 11 February 2022 / Accepted: 15 February 2022 / Published online: 27 February 2022

(C) Beijing Normal University 2022

\begin{abstract}
Our daily lives have been transformed by mobile smart devices. Due to the sudden impact of the coronavirus (Covid-19) on education, the importance of mobile devices for communicating with teachers and students has risen to a new level of prominence. The Web of Science and Scopus databases were used to conduct a systematic review of the research on mobile collaborative learning in engineering education. The purpose of this review is to ascertain the degree to which research on mobile collaborative learning has been conducted in the field of engineering education between 2010 and 2020. A total of 48 articles were reviewed to ascertain the research methodologies and area of study, as well as to provide an updated review of studies on mobile collaborative applications, particularly in the field of engineering education. Among the most significant findings is that the majority of publications make use of augmented reality and mobile application development. According to the review, the majority of studies were conducted in the fields of computer sciences, electronic engineering, and artificial intelligence.
\end{abstract}

Keywords Collaborative learning · Engineering education · Mobile learning · Systematic review

Anuradha Peramunugamage

anuradhaperamunugamage@gmail.com; anuradhask@uom.lk

Uditha W. Ratnayake

udithaw@ou.ac.lk

Shironica P. Karunanayaka

spkar@ou.ac.lk

1 Department of Electrical and Computer Engineering, Faculty of Engineering Technology, The Open University of Sri Lanka, Nawala, Nugegoda 10306, Sri Lanka

2 Department of Secondary and Tertiary Education, Faculty of Education, The Open University of Sri Lanka, Nawala, Nugegoda 10306, Sri Lanka 


\section{Introduction}

Mobile phone markets are always evolving due to the adoption of new technologies. Mobile phones are not simply telephones; they are also minicomputers, video and still cameras, personal digital assistants, audio recorders, and GPS navigators. They also have the capability to employ smart Apps via the integrated Internet of Things. The proliferation of lightweight mobile technologies has ushered in a new era of disruptive technology in education. As a result, it enables students to participate and interact in both formal and informal learning environments, as students can access learning resources at any time from any location. Mobile learning, or m-learning, is a term that refers to this type of learning (Dyson et al., 2009). Mobile technology enables students to access a range of learning techniques regardless of their location or time constraints (Tawfik et al., 2013). Mobile learning (mLearning) is gaining popularity due to several benefits it provides to both teachers and students, including cost effectiveness, mobility, quick connectivity, and context sensitivity. Additionally, it facilitates interaction between students and professors by fostering collaborative learning, interactivity, and rapid feedback (Kukulska-Hulme et al., 2011; Neto \& Williams, 2013). There are several potential benefits and limitations to the use of technologies to improve educational access. The following are some of the benefits of mobile learning technologies: (a) they remove geographical constraints in learning; (b) they help students to develop a self-centered learning pedagogy; and (c) they facilitate an efficient communication mechanism for learning as well as endorsement and review of content between teachers and learners (Chew et al., 2018; KukulskaHulme, 2007; Kukulska-Hulme et al., 2011; Lee, 2011).

Research in computer-supported collaborative learning (CSCL) is concerned with investigating how people can learn together with the assistance of computers as an emerging field of learning sciences (Balakrishnan, 2015; Hinze-Hoare, 2007); whereas Mobile Computer-Supported Collaborative Learning (mCSCL) research is concerned with investigating how people can learn together with the assistance of mobile devices(Amara et al., 2016; Caballé et al., 2010; Huang et al., 2010).

As described by Chatti et al. (2012) mobile learning becomes interactive when used in a collaborative environment (Lee, Clark and Nosekabel, 2011). It provides both formal and informal learning associated with interaction and exchange of information. Spikol (2008) describes how collaborative learning through mobile devices has been investigated mainly because of the availability and mobility offered by these devices. According to Jain et al. (2011), collaborative mobile learning is an activity that allows transparent collaboration by empowering the social negotiation space of group members, coordination between the activity states, encouraging members' mobility, possibility of mediation in interactivity, organization of the managed material and enabling students to collaborate in groups through wireless network supporting social face-to-face communication.

By integrating a variety of media like video clips, instant messages, photos, music, simulations, and animations, collaboration can be entertained 
(Fakomogbon \& Bolaji, 2017). The different media mixes in mobile learning instructional content create a meaningful engagement of the learner's intellectual capacity through active involvement in a collaborative learning setting. In addition to using the mobile device as a tool or platform for Computer-Supported Collaborative Learning (CSCL), researchers have claimed that $\mathrm{mCSCL}$ can increase a learner's active participation in activities by providing more opportunities for instant interaction between a learner and his or her peers via the use of mobile devices (Patten et al., 2006; Ryu \& Parsons, 2012; Amara et al., 2016). Therefore, in the mobile learning environment, lecture video, lecture notes, audio, quiz and test, assignment, discussion, and grade components are generally included (Lee, Clark and Nosekabel, 2011). As a result, various tools and systems have increasingly been developed for or integrated into mobile devices for mCSCL. These activities have taken place in a variety of settings, including physical, social, and virtual environments.

In light of the widespread use of mobile devices in education, research on mobile learning is rapidly expanding (Bhati \& Song, 2019; Cabada, Barrón Estrada, and Reyes García 2011; Dyson et al., 2009; Lu et al., 2015), and as a result, it has been reviewed in many publications (Connolly et al., 2012; Hwang \& Tsai, 2011; Hwang and Wu 2014; Sum Cheung and Foon Hew 2009; Wu et al., 2012; Xia \& Zhong, 2018; Zydney \& Warner, 2016) Specific aspects of mobile learning were examined in some reviews, such as mobile learning games (Avouris \& Yiannoutsou, 2012; Malegiannaki \& Daradoumis, 2017), mobile computersupported collaborative learning (Pimmer et al., 2016; Swid, Hsu, and Wang 2018), or mobile apps (Atawneh et al., 2020; Avouris \& Yiannoutsou, 2012; Xia \& Zhong, 2018; Zydney \& Warner, 2016).

Fu and Hwang (2018) undertook a study of the literature on collaborative learning facilitated by mobile technologies. They discovered that collaborative learning through mobile devices is a fast emerging study topic that has the potential to boost learners' cognitive and metacognitive growth. As shown on Table 1, several valuable systematic literature surveys was done on mobile learning. However, certain areas require further investigation. For instance, there is considerable potential for mobile learning to be used in the field of engineering education, owing to several factors that make it unique and well-suited to the affordances of mobile technology. The majority of engineering activities occur outside of the classroom.

However, no systematic review on mobile collaborative learning for engineering education has been published in the last decade. There were five review articles, each focusing on a different aspect or dimension of the advancement of mobile collaborative learning. Thus, the purpose of this study was to determine how mobile collaborative learning research is conducted in the field of engineering education. The purpose of this research review is to provide an updated overview of studies on mobile applications, specifically in the field of engineering education. We proposed the following research questions.

(1) During 2010 to 2020, what are the research methodologies adopted for studying mobile collaborative learning in engineering education? 


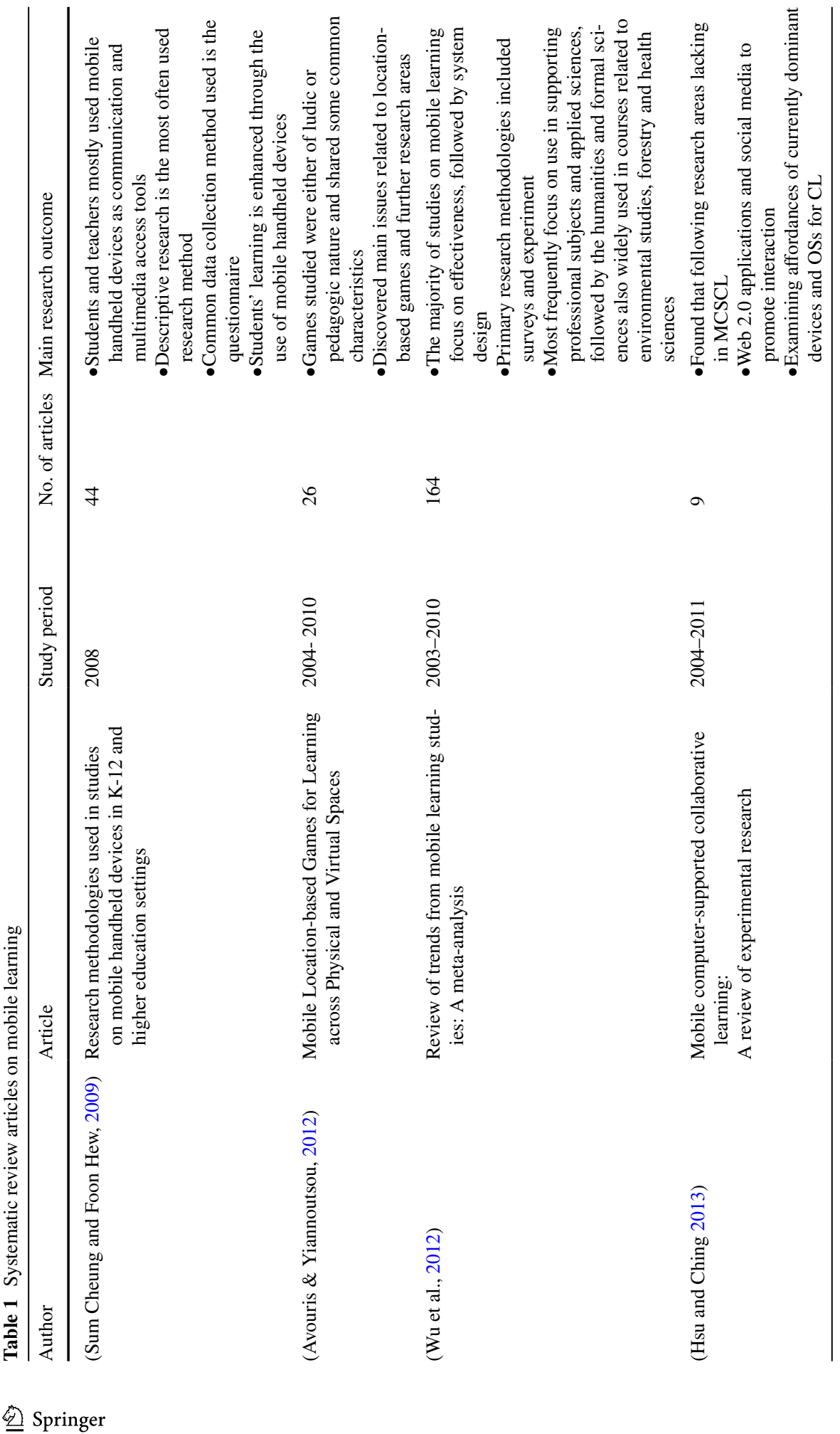




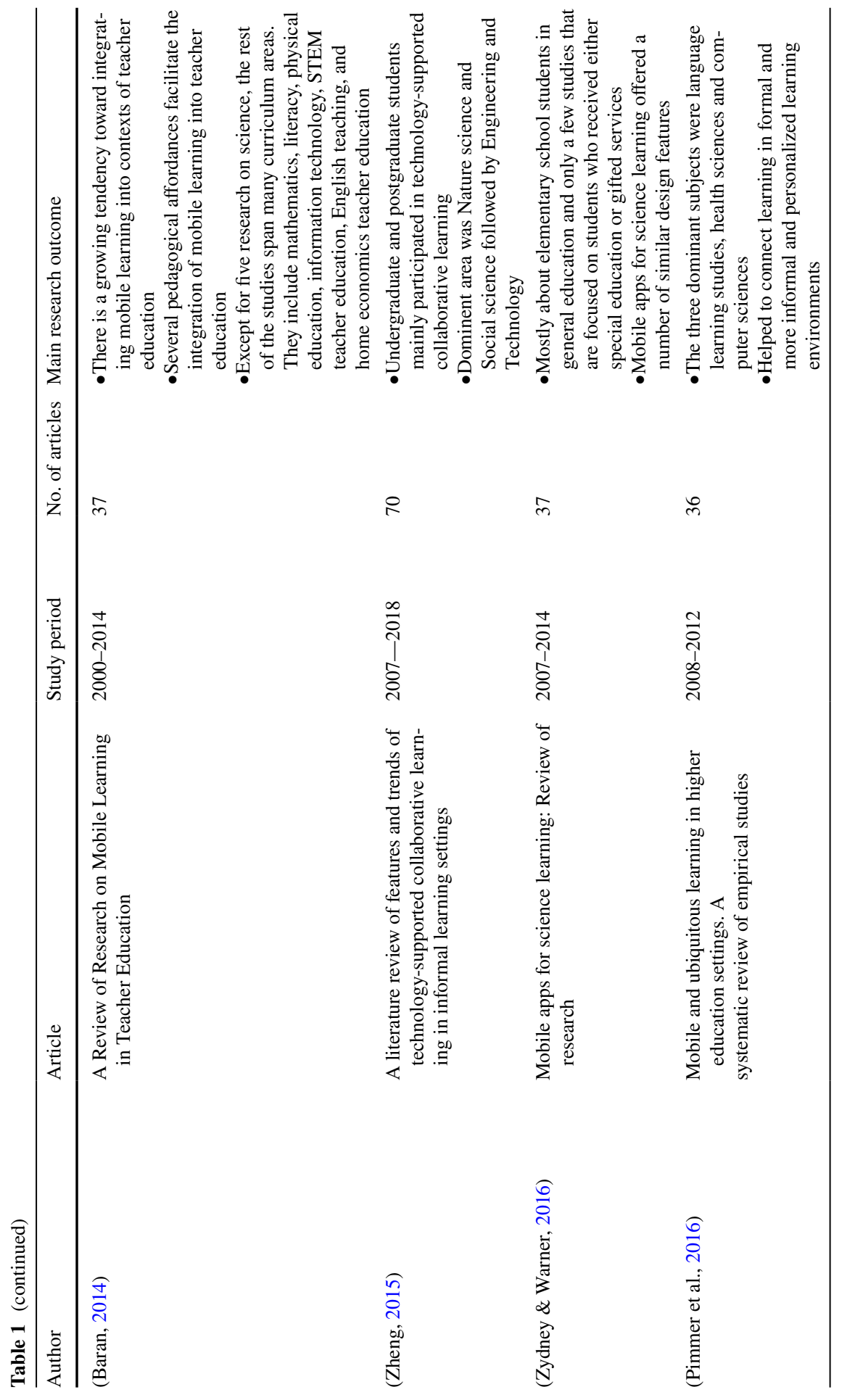




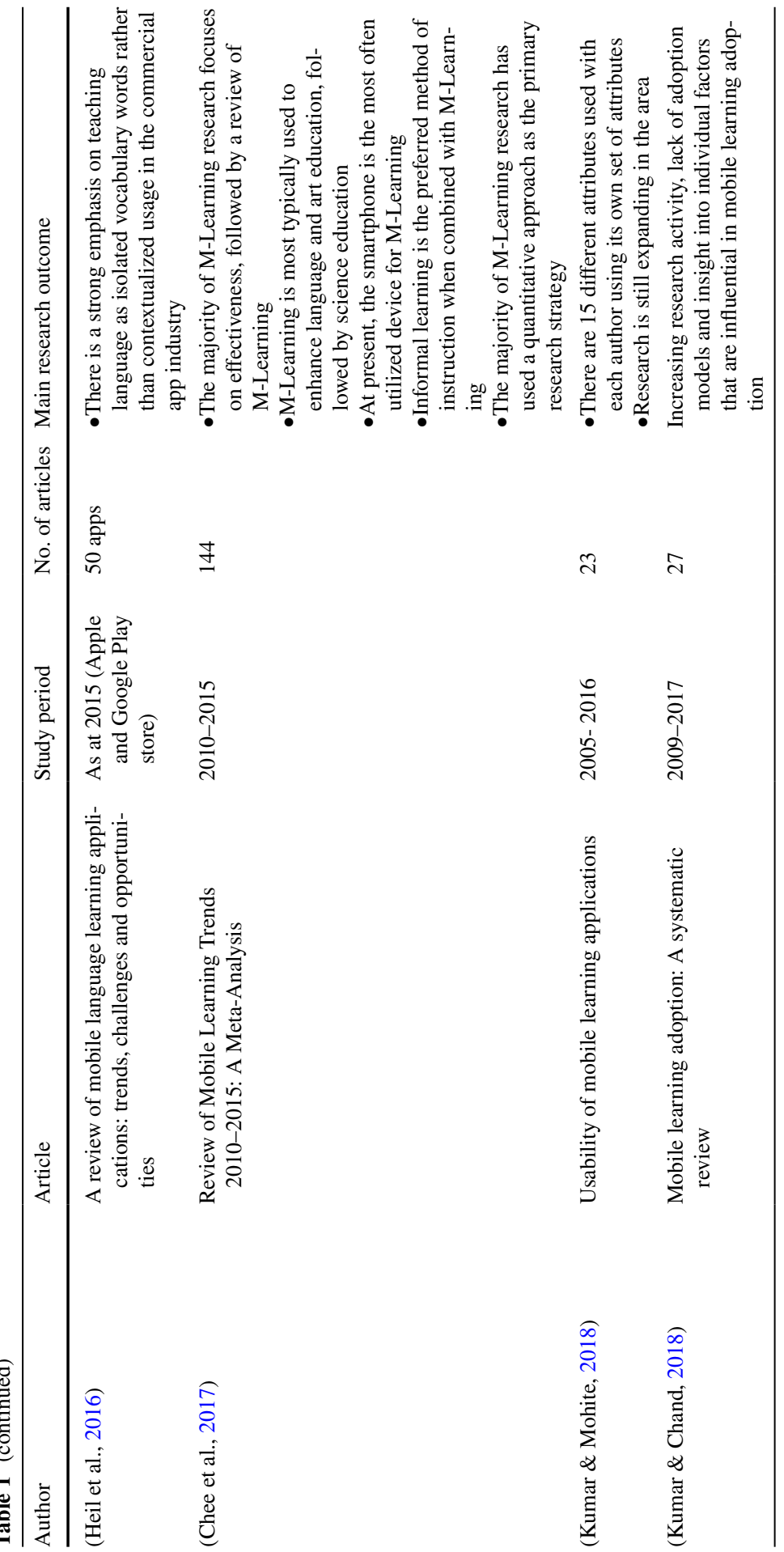




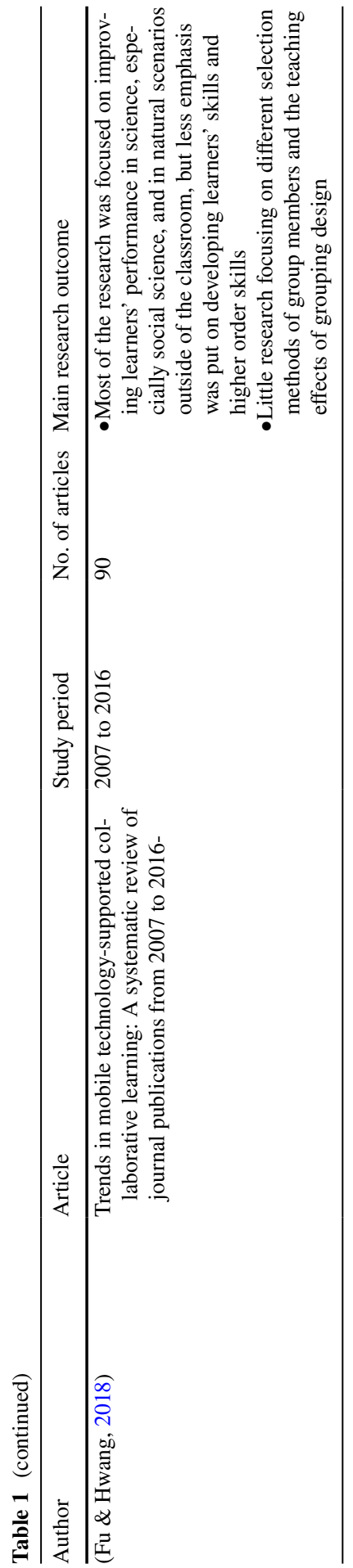


(2) During 2010 to 2020 , what are learning environments used in mobile collaborative learning for engineering education?

(3) During 2010 to 2020, what are the theoretical foundations widely applied for mobile collaborative learning in engineering education?

This paper first describes how the literature review was carried out. Second, the results of the review are presented followed by discussions of methodological issues and potential directions for future mobile collaborative learning in engineering education research. Finally, conclusions are drawn.

\section{Method of article selection}

The data collection and analysis process was guided by previous studies such as Hsu and Ching (2013) and Hwang and Tsai (2011), which requires conducting a review based on quality publications. For literature reviews conducted concerning higher education, the Web of Science (all databases) and SCOPUS databases were used to search for mobile collaborative learning in engineering education which has been recommended by several previous studies. Therefore, in this study, the Boolean expressions ("collaborative learning" OR "cooperative learning") AND ("m-learning" OR "mobile learning" OR "ubiquitous learning") were used to search for publications from the Web of Science database and SCOPUS databases. These databases were chosen because they are known for encompassing high-impact, highquality journals indexed in the Science Citation Index and the Social Citation Index. Both databases were searched with the same Boolean expression. Related terms were used to create a more comprehensive search. For example, alternative keywords for mobile included ubiquitous and m-learning; the alternative keyword for collaborative was cooperative; and the alternative keywords for engineering were Computer Science Interdisciplinary Applications or Education Scientific Disciplines or Engineering Electrical Electronics or Computer Science Information Systems or Telecommunications or Computer Science Artificial Intelligence or Computer Science Software Engineering or Engineering Multidisciplinary or Computer Science Cybernetics or Computer Science Hardware Architecture or Computer Science Theory Methods or Automation Control Systems or Robotics.

The authors developed this criteria list based on previously published criteria (Moher et al. 2009), but narrowed it further during the article review to conduct a more focused, in-depth review of the studies. To locate high-quality literature, the SCI and SSCI databases were chosen as target databases for literature searches. Additionally, the period was set from 2010 to 2020, and the literature types were designated as "articles" under the recommendations of several previous review studies (Hwang \& Tsai, 2011; Wu et al., 2012; Zydney \& Warner, 2016). After removing duplicates, 182 articles remained for further selection. We reviewed titles and abstracts to identify papers that met the following criteria: (1) peer-reviewed journal articles (2) full-text access and (3) undergraduate education (4) engineering education-related (5) mobile collaborative learning; and (6) investigation of mobile collaborative learning platforms, including their development and evaluation. After the 
review of abstracts, 76 studies were deleted because they did not meet the inclusion criteria.

Several exclusion criteria were also applied: (1) used for professional learning (e.g., teacher education, engineering, the management or engineering professionals), (2) emphasized app design and development as opposed to student outcomes, (3) aimed exclusively at outcome measures unrelated to engineering learning (e.g., usability, engagement, interest), (4) directed at laptop use, robots, or wearable systems as opposed to tablets or phones, (5) focused on student-created apps (e.g., experiments, prototypes, not available in the market) and (6) did not include an in-person component. Based on the established inclusion criteria, the abstracts of the 182 articles were read and analyzed, and irrelevant articles were excluded. Finally, 110 articles were chosen for inclusion in the analysis. Figure 1 shows the process and methods of data searching and collection. Sixty-one full-text articles were reviewed and sixty-two articles were eliminated from the analysis due to the unavailability of the full-text, being focused on language learning or other management activities or case studies or samples but not for undergraduate education. A total of 48 articles met the criteria to be included in the final review and were considered for the qualitative

\section{Systematic Review on Mobile Collaborative Learning for Engineering Education}

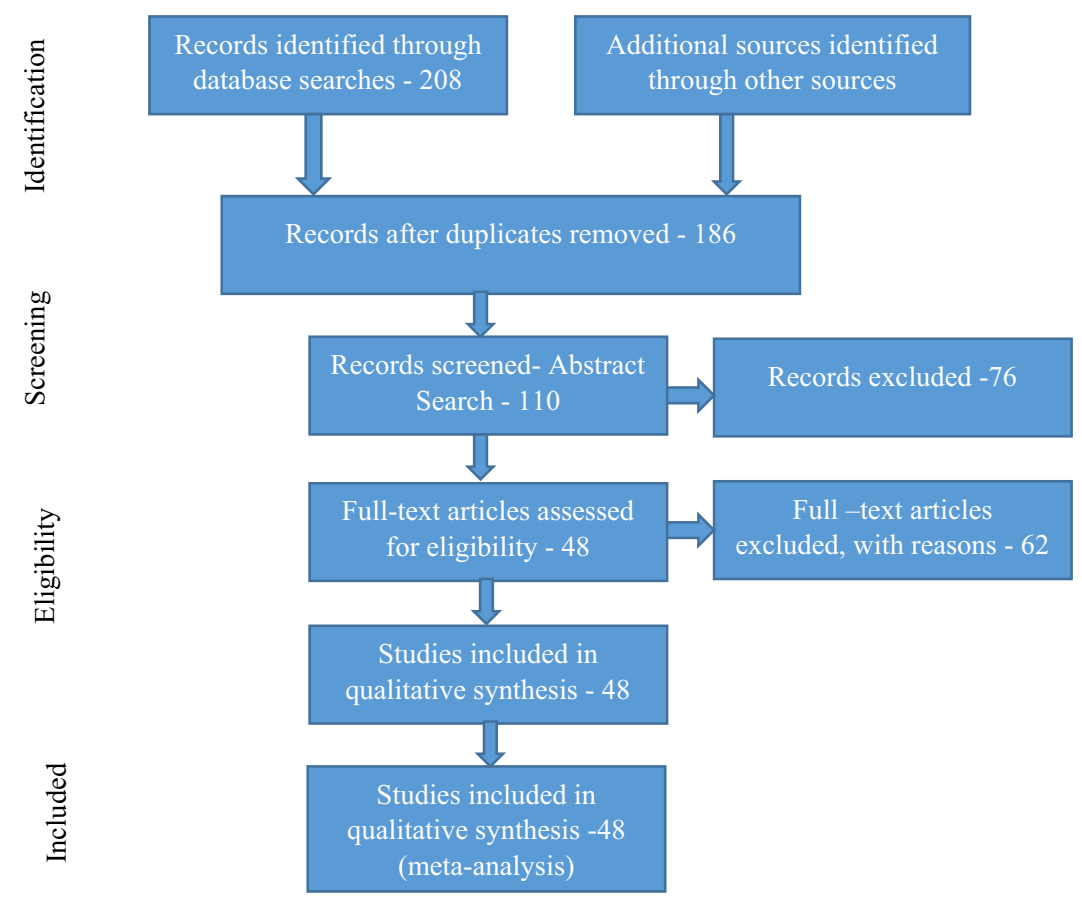

Fig. 1 PRISMA flow: data extraction procedure 
Table 2 Distribution of eligible articles in all referred journals

Journal

Num-

ber of

papers

Artificial Life and Robotics, Electronics, IEEE transactions on Industrial Electronics, IEEE 1

Transactions on Services Computing, Innovations in Education and Teaching International, Interactive Learning Environments, International Journal of Computer Applications in Technology, International Journal of Advanced Computer Science and Applications

Eurasia Journal of Mathematics Science and Technology Education,

British Journal of Educational Technology, Computer Applications in Engineering Education, International Journal of Emerging Technologies in Learning, International Journal of Mobile and Blended Learning, Telematics and Informatics

Expert systems with applications

Computers \& Education, Educational Technology \& Society

IEEE Transactions On Learning Technologies

synthesis/meta-analysis. According to the distribution of eligible journal articles in Table 2, IEEE Transactions on Learning Technologies contributed to the publication of five articles on mobile collaborative learning in the field of engineering education. During the last decade, four (4) articles from each of the journals Computers \& Education and Educational Technology met the research criteria.

\section{Data distribution}

After content-coding and analysis, we classified the 48 articles by publication year and conducted a preliminary examination of the data sources to determine whether the definition of mobile collaborative learning in engineering education was consistent with the research findings. The data distribution is depicted in Fig. 2. As can

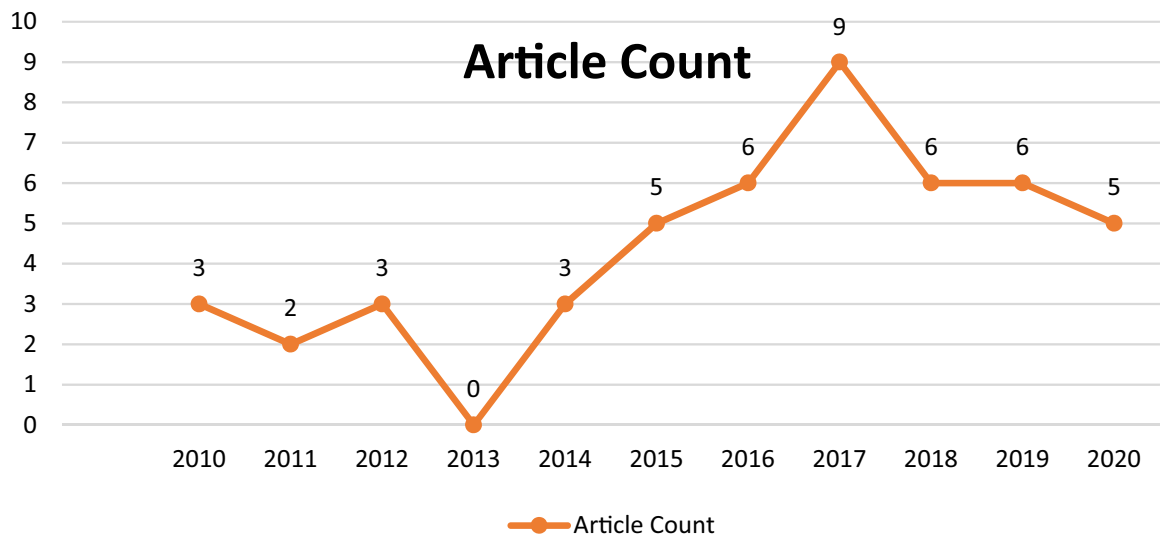

Fig. 2 Distribution of mobile collaborative learning literature in engineering education during 20102020 
be seen, the amount of literature on mobile collaborative learning in engineering education has gradually increased over the last decade, which corresponds to the regularity with which new items are developed. Hsu and Ching (2013) summarized research on mobile computing-enabled collaborative learning that was published in peer-reviewed journals between 2000 and 2011, encompassing a total of nine studies. Before 2013, there was little research on mobile collaborative learning, which is consistent with the findings of this study (Hsu and Ching 2013). The data were established to be correct, and thus the study could progress to the next stage of the coding scheme.

The word cloud is a widely used technique for visualizing the key terms contained in the title, abstract, and keywords of selected papers in review studies(Asadi et al., 2017; Tricco et al., 2016). The larger the word in the graphical representation, the more frequently it appears in the keywords of the chosen papers. Figure 3 depicts a word cloud created from the keywords extracted from selected papers in this study. This illustration can assist in visualizing the purpose and structure of the selected publications. As illustrated in Fig. 3, the term "collaborative" is the most frequently used in the selected studies (28 times), followed by "mobile" (26 times), "collaborative learning" (25 times), and "mobile learning" (13 times).

\section{Coding scheme and process}

In order to systematically examine the development status and trends of mobile collaborative learning in engineering education research from 2010 to 2020 from

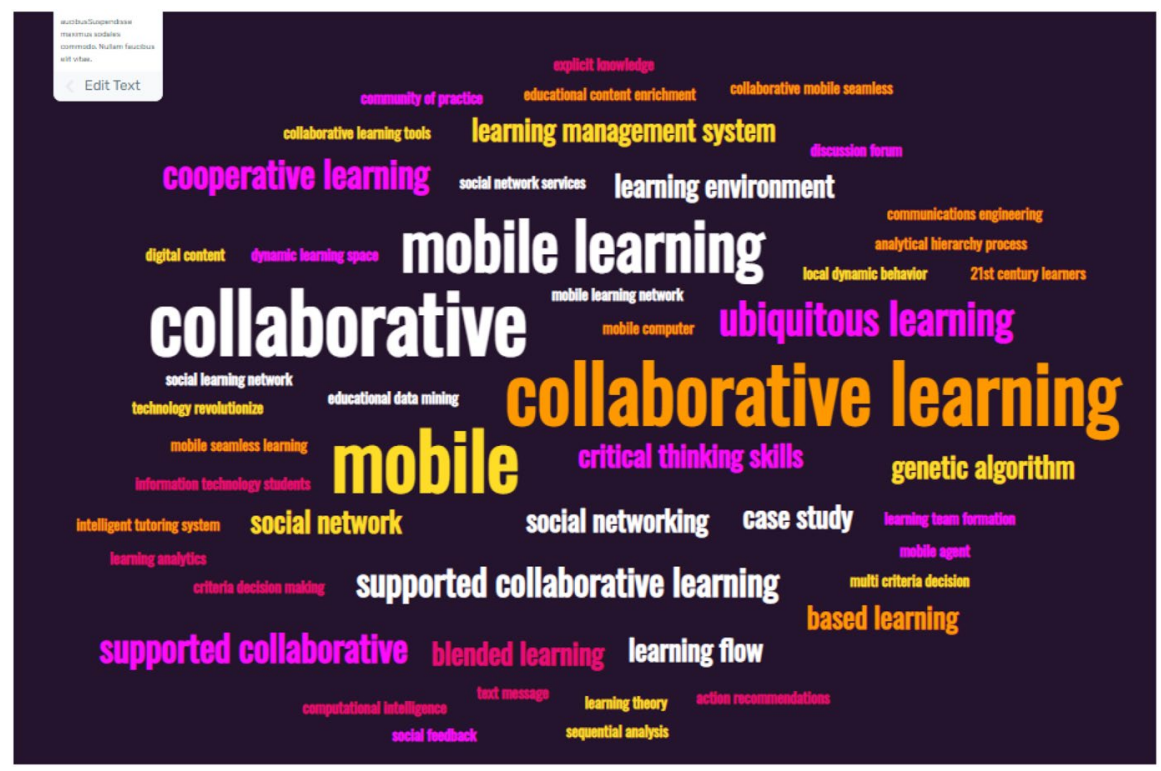

Fig. 3 Word cloud for keywords 
different dimensions, the coding scheme was established from diverse dimensions, learning environment, research participants and subjects, research methodology, and type of interactions for collaborative learning.

(1) Codes for the learning environment.

The coding scheme of the mobile learning environment includes classroom or laboratory, school campus, LMS, and non-specified.

(2) Codes for research participants and subjects.

The codes for participants and subjects were proposed by Hwang and Tsai (2011). The codes for participants include engineering undergraduates, others, and non-specified, while the codes for learning subjects include engineering or computers, science (e.g., physics, chemistry, other and non-specified).

(3) Codes for collaborative learning strategies.

Johnson et al. (1998) pointed out eight commonly used collaborative learning strategies. Accordingly, the coding scheme for collaborative learning strategies included learning together, team games tournaments, group investigation, academic controversy, jigsaw II, student team achievement divisions, team-assisted individualization, cooperative integrated reading and composition, other, and non-specified (Johnson, Johnson, and Smith 1998)

(4) Codes for research methods.

Pimmer et al. (2016) divided research methods into quantitative, qualitative, mixed-method, case studies, and others were added in the coding scheme (Pimmer et al., 2016).

(5) Codes for interactions.

As Moore et al. (1989) introduced there are four types of interactions. Accordingly, the coding scheme for interactions is learner-content, learner-instructor, learner-learner, and learner-interface (Jayaweera, 2019; Moore, 1989).

\section{Overview of reviewed studies}

Of the 48 studies reviewed from 2010 to 2020, the majority of studies (40 articles) were published after 2013. The number of student participants in the studies ranged from 10 to 1121 with a median of about 23 as shown in Table 3 . The research contribution of 48 articles can be categorized into six main thematic areas as shown in Table 4, such as Collaborative Learning Contribution, Mobile App development as a supporting tool for collaborative learning, use of Web 2.0 technologies to enhance collaborative learning, the introduction of models for mobile collaborative learning, and algorithm generation for group formation and integration.

In engineering education, the development of mobile agents or multi-agent-based architectures was extremely popular. There is only one article in the literature that discusses the use of augmented reality technologies in engineering education over the last decade. Additionally, mobile instant messaging, SMS, chat applications, and a forum were evaluated as mechanisms for collaborative learning.

Engineering education also has a demand for mobile application development. Eight journal articles described artificial intelligence-enhanced mobile game-based 
Table 3 The number of student participants in the studies

\section{Author/s}

Alnabhan et al. (2018)

Atawneh et al. (2020)

Huang et al. (2014)

Temdee (2014)

Ryu et al. (2012)

Lim et al. (2019)

Temdee (2016)

Chung et al. (2017)

Lee et al. (2016)

Sun et al. (2016)

Manathunga and Hernandez-Leo (2018)

Reychav et al. (2015)

Alioon and Delialioglu (2019)

Ma et al. (2020)

MacCallum et al. (2017)

Domínguez et al. (2017)

Albers et al. (2017)

Ramírez-Donoso et al. (2017)

Brett (2011)

Chew et al. (2018)

Dyson et al. (2018)

Zhu et al. (2019)

Chen et al. (2015)

Snoussi et al. (2020)

Muhisn et al. (2019)

Araújo et al. (2017)

Lopez Garcia et al. (2016)

Lin et al. (2016)

Son et al. (2016)

Chuang (2015)

Laru et al. (2015)

Balakrishnan B

Zhou et al. (2014)

Huang et al. (2010), Choi and Kang (2012), Scott and Benlamri (2010), Bhati and Song (2019), Calvo et al. (2017), Sun et al. (2018), Osman et al. (2018), Acedo et al. (2017), Cabada et al. (2011), Troussas et al. (2020), Yafie et al. (2020), Garshasbi et al. (2019), Yannibelli and Amandi (2012), Al-Abri et al. (2017)

Rodriguez-Andina et al. (2010)
Number of students/ Sample Size

135

26

63

50

45

14 and 21

50

58 and 61

25

100

100

251/112

30 and 33

165

30

25

118

68 and 34

1121

7 teachers

316

144

80160177

284

109

121

21

simulated 50 real 117

258

200

$10|22| 21$

30

57

Not mentioned

No student involves 
Table 4 Six thematic areas of research articles during 2010 to 2020

\section{Author}

(Atawneh et al., 2020; Ryu \& Parsons, 2012; Temdee, 2014, 2016)

(Fonseca Escudero et al., 2017)

(Bhati \& Song, 2019; Brett, 2011; Lim et al., 2019)

(Calvo et al., 2017)

(Reychav et al., 2015)

Mobile App development [8] 17\%

(Chung et al., 2017)

(Lee et al., 2016)

(Alioon \& Delialioğlu, 2019)

Alnabhan et al. (2018)

(Troussas, Krouska, and Sgouropoulou 2020)

(Chew et al., 2018)

(Son et al., 2016)

(Snoussi et al., 2020)

Web 2.0 technologies [10] $21 \%$

(Huang et al., 2010)

(Choi \& Kang, 2012)

(Sun \& Shen, 2016)

(Cabada et al., 2011)

(Manathunga \& Hernández-Leo, 2018)

(Balakrishnan, 2015)

(Huang et al., 2013)

(MacCallum et al., 2017)

(Albers et al., 2017)

(Laru et al., 2015)

(Muhisn et al., 2019)

Model Creation [9] 19\%

(Scott \& Benlamri, 2010)
Collaborative learning contribution [10] 21\%

A mobile agent, multi-agent-based architecture

Using digital image processing techniques, and (b) creating 3D virtual environments in different formats, including AR

Mobile instant messaging, SMS

Chat applications

Forum -MOOC

Push-pull technology-based mobile learning system Mobile learning game designed

Mobile game-based learning application which incorporates artificial intelligence techniques

m-learning context prototype

Mobile game-based learning application which incorporates artificial intelligence techniques

Game-based learning, mobile learning, flipped classroom, and seamless learning

MyResponse mobile app

Collaborative mobile seamless learning (CMSL) based on android apps

Web 2.0 learner-oriented mobile learning knowledge networks forming of collaborative groups dynamically

Helps in obtaining learning-related information on the Internet through social network services

The cloud-based Jigsaw Classroom

Software tool (EDUCA) to create adaptive learning material in a Web 2.0 collaborative learning environment

It includes an authoring tool training workshops, valued positively PyramidApp features

Google Docs and adoption of CSCL using Google Docs

Jigsaw-based cooperative learning strategy with Google +

Web 2.0, Google Drive, Google +, social media and mobile tools

WhatsApp, Instagram, Twitter, KIK

Write blog entries cloud-based Wikispaces wiki service Flickr, WordPress, and Wikispaces

Integrating social media tools

Near Field Communication (NFC) technology 
Table 4 (continued)

\begin{tabular}{|c|c|}
\hline Author & Collaborative learning contribution [10] $21 \%$ \\
\hline $\begin{array}{l}\text { (Osuna Acedo, Gil Quintana, and Cantillo Valero } \\
\text { 2017) }\end{array}$ & Evaluation of the authoring tool \\
\hline (Ma et al., 2020) & $\begin{array}{l}\text { Collaborative learning, connectivism, and experien- } \\
\text { tial learning }\end{array}$ \\
\hline (Osman et al., 2018) & $\begin{array}{l}\text { The model was utilized to design a questionnaire for } \\
\text { a survey about user acceptance }\end{array}$ \\
\hline (Dyson \& Frawley, 2018) & Self-reported learning \\
\hline (Zhu et al., 2019) & $\begin{array}{l}\text { Transition-rate analysis, entropy-analysis, and } \\
\text { sequential pattern mining to analyze the chat } \\
\text { message }\end{array}$ \\
\hline (Chen and;Dong, Jang;Anthony 2015) & $\begin{array}{l}\text { Digital content can be provided as personalized } \\
\text { assistance }\end{array}$ \\
\hline (Yafie et al., 2020) & $\begin{array}{l}\text { Everyday Informal Learning through what is being } \\
\text { offered via self-direction }\end{array}$ \\
\hline \multicolumn{2}{|l|}{ Group Formation [3] 6\% } \\
\hline (Garshasbi et al., 2019) & $\begin{array}{l}\text { Developed intelligent algorithm in the optimal } \\
\text { group formation process }\end{array}$ \\
\hline (Yannibelli \& Amandi, 2012) & $\begin{array}{l}\text { Deterministic crowding evolutionary algorithm to } \\
\text { assist teachers when forming well-balanced col- } \\
\text { laborative learning teams }\end{array}$ \\
\hline (Lin, Chang, and Chu 2016) & $\begin{array}{l}\text { Genetic Algorithm }(\mathrm{GA}) \text { —facilitating the tradeoff } \\
\text { multi-objective grouping optimization }\end{array}$ \\
\hline \multicolumn{2}{|l|}{ Learning Environment [8] 16\% } \\
\hline (Al-Abri et al., 2017) & $\begin{array}{l}\text { Integrated into the Classroom experience, a multi- } \\
\text { media capture platform for educational environ- } \\
\text { ments }\end{array}$ \\
\hline (Araújo et al., 2017) & Classroom eXperience (CX) platform \\
\hline (Lopez Garcia et al., 2016) & Remote Labs, Debates, Work in groups \\
\hline (Chuang, 2015) & $\begin{array}{l}\text { Smartphone-Supported Collaborative Learning } \\
\text { System (SSCLS) }\end{array}$ \\
\hline (Sun et al., 2018) & A smart microlearning environment (MOOC) \\
\hline (Ramírez-Donoso et al., 2017) & LMS-MOOC \\
\hline (Zhou et al., 2014) & Moodle-based learning system \\
\hline (Rodriguez-Andina et al., 2010) & About the novel approaches \\
\hline
\end{tabular}

learning applications. It met the research's search criteria, and the majority of them have attempted to increase interactions through the development of mobile gamebased learning applications. As part of collaborative learning activities, Web 2.0 technologies such as cloud-based Jigsaw Classroom, Google Docs, WhatsApp, Instagram, Twitter, KIK, write blog entries, cloud-based Wikispaces, wiki service, Flickr, WordPress, and Wikispaces were used.

The development of algorithms for optimal group formation and team composition, as well as the introduction of new models for collaborative learning, have made a significant contribution to engineering education. MOOCs, virtual labs, and 
learning management systems have all been used as collaborative learning environments in engineering education over the last decade.

When subject areas of review articles are analyzed, the majority of research is conducted in computer science, electronic, or electrical engineering. According to the review, 32 articles failed to specify the subject area for which the research was evaluated or tested. The most frequently repeated subjects in the selected studies are "artificial intelligence" (3 times), "information and communication technologies" (2 times), and "learning technologies" (2 times).

As shown in Table 5, Nine articles were used mixed-method, case study, and experimental designs to analyze the aforementioned learning environments and the effectiveness of developed models and algorithms. Since it would be eassy for researcher to practice with different sample sizes and participants with the changes of demographic factors. To create mobile applications, learning environments, and agent-based systems, methodologies of action research, prototyping, and experimentation were used enormously (14 articles), because those research methods

Table 5 Distribution of research methodologies used in review articles

\begin{tabular}{|c|c|}
\hline Authors & Research methodology \\
\hline $\begin{array}{l}\text { (Albers et al., 2017; Atawneh et al., 2020; Brett, 2011; } \\
\text { Calvo et al., 2017; Dyson \& Frawley, 2018; Osuna } \\
\text { Acedo et al., 2017; Troussas et al., 2020; Zhou et al., } \\
\text { 2014) }\end{array}$ & Mixed method, Case studies \\
\hline $\begin{array}{l}\text { (Cabada et al., 2011; Chung et al., 2017; Fonseca } \\
\text { Escudero et al., 2017; Lee et al., 2016; Lin et al. } \\
\text { 2016; Ma et al., 2020; Manathunga \& Hernández- } \\
\text { Leo, 2018; Son et al., 2016) }\end{array}$ & Experimental design \\
\hline $\begin{array}{l}\text { (Laru et al., 2015; Lopez Garcia et al., 2016; Mac- } \\
\text { Callum et al., 2017; Ryu \& Parsons, 2012; Scott \& } \\
\text { Benlamri, 2010) }\end{array}$ & Case studies \\
\hline $\begin{array}{l}\text { (Choi \& Kang, 2012; Garshasbi et al., 2019; Scott \& } \\
\text { Benlamri, 2010) }\end{array}$ & Action research qualitative research approach \\
\hline $\begin{array}{l}\text { (Balakrishnan, 2015; Huang et al., 2010; Muhisn et al., } \\
\text { 2019; Osman et al., 2018; Reychav et al., 2015; } \\
\text { Snoussi et al., 2020; Temdee, 2016) }\end{array}$ & questionnaire surveys and Empirical Study \\
\hline $\begin{array}{l}\text { (Alioon \& Delialioğlu, 2019; Bhati \& Song, 2019; } \\
\text { Ramírez-Donoso et al., 2017) }\end{array}$ & design-based research approach, mixed methods \\
\hline $\begin{array}{l}\text { (Al-Abri et al., 2017; Garshasbi et al., 2019; Yannibelli } \\
\text { \& Amandi, 2012) }\end{array}$ & Algorithm generation and Experiments \\
\hline (Sun et al., 2018) & Prototype \\
\hline (Chew et al., 2018; Rodriguez-Andina et al., 2010) & Qualitative methods \\
\hline (Zhu et al., 2019) & Control group \\
\hline (Lu et al., 2015; Temdee, 2014) & pre-test as well as a post-test \\
\hline (Yafie et al., 2020) & $\begin{array}{l}\text { Ghirardini model is a modification of ADDIE } \\
\text { and Expert Judgment }\end{array}$ \\
\hline (Araújo et al., 2017) & As a proof of concept \\
\hline (Chuang, 2015) & Delphi method \\
\hline
\end{tabular}


supported to researcher to carry out the design or artifact iterative incremental manner and researchers emphasized the empirical experience in both experimental environments and real scenarios. Additionally, qualitative and quantitative analyses were discovered to carry out the research, although the amount of qualitative research was relatively small.

\section{Discussion}

With the integration of new technology, distinct classrooms and learning environments (e.g., game-based learning, flipped classroom, seamless learning) are being displaced by new pedagogies, applications, and concepts in the field of educational technology. It has grown rapidly and vitally. The integration of mobile smart devices has had a significant impact on modern education. Harasim et al. (1995) defined online collaborative learning as "a process in which two or more individuals work collaboratively to create meaning, explore a topic, or improve skills."Mobile collaborative learning contributed significantly to increasing mobility and collaboration without regard for time, pace, or location constraints (Makewa et al., 2014).

From 2010 to 2020, a review of the research literature reveals a range of approaches and methodologies, including experimental, action, case study, Delphi, qualitative, quantitative, and design research as shown in Table 5. The methods vary according to the theoretical framework used by the researcher, and the studies also vary in their goal of collaborative learning, which may include app development, enhancing interactions, improving content sharing capabilities, developing mechanisms or algorithms for effective group formation, supporting asynchronous and synchronous communication, and utilizing various applications, such as platforms. For example, Acedo et al. (2017) developed a bidirectional communication model that engages students by making them feel like co-participants in a unique experience. Additionally, Arajo et al. (2017) developed an educational support tool for recording classes in instrumented settings, storing captured multimedia content, and making it accessible to students for revision. It is a significant effort and a contribution to the mobile learning environment.

The review of the literature revealed a dearth of research on the effects of group size on mobile collaborative learning. However, the learning group should be small enough to allow students to participate fully and to foster group cohesion (Barker, 2007; Tuckman, 1965). A larger group size may detract from the learner's experience. Groups can be formed in a variety of ways. A group's membership can be determined by the teacher, selected by students, or randomly assigned, and the groups can be heterogeneous or homogeneous. In this study, random group formation and student-selected groups were discovered in review articles (Lopez Garcia et al., 2016; Sun \& Shen, 2014; Zhu et al., 2019). In the field of engineering education, it is critical to have a diverse group of members; these groups expose the learner to a variety of perspectives on issues and tasks, based on the diverse backgrounds and experiences of the group members, as revealed in the literature. Lin et al. (2016) created a web-based group support system to assist educators in grouping homogeneous intergroup and heterogeneous intragroup members appropriately. However, and Garshasbi et al. (2019) developed an 
intelligent algorithm for the optimal group formation process that efficiently divides learners into inter-homogeneous and intra-heterogeneous learning groups. Additionally, Yannibelli and Amandi (2012) created an algorithm to aid teachers in forming balanced collaborative learning teams.

When it comes to collaborative learning, many different methodologies can be used. Some of the most common are think-pair-share; informal collaborative learning groups; and formal collaborative learning groups. Other collaborative learning methodologies include problem-based and collaborative-based groups; and jigsaw collaborative learning. In accordance with the review articles, the majority of the articles were devoted to formal collaborative learning as well as jigsaw collaborative learning (Huang et al., 2010, 2013; Sun \& Shen, 2016). Yafie and colleagues (2020) considered informal collaborative mobile learning based on Android apps as part of their research (Yafie et al., 2020).

As defined by the definition of collaborative learning, student interaction is critical. In technology-enhanced learning environments, various types of interaction occur. As an example, there are learner-content (LC), learner-teacher (LT), learner-learner (LL), and learner-interface (LI). Nonetheless, there are five studies (Atawneh et al., 2020; Calvo et al., 2017; Chuang, 2015; Lim et al., 2019; Temdee, 2016) that focused primarily on interaction monitoring in this study. When researchers were developing agentbased applications, they took into account the aforementioned interaction types. For instance, Atawneh et al. (2020) defined four distinct types of agents: learner agents, teacher agents, device agents, and social agents. Lim et al. (2019) used mobile instant messaging to attempt to increase LT and LL interactions. Temdee, P. (2014) developed an agent-based model for collaborative interaction. Additionally, Calvo et al. (2017) enhanced interactions through the use of the Edmodo chat application.

\section{Conclusions}

Based on a 10-year review study conducted in recent years, this paper presents an investigation into the use of mobile collaborative learning for engineering education during the last decade (2010-2020). Using specific search terms keyed into two large scientific electronic databases, we were able to identify forty-eight (48) papers that discussed the use of mobile collaborative learning in engineering education. It appears from the review articles that mobile-based collaborative learning is becoming increasingly popular, particularly in engineering education where the majority of activities were experimental and student-oriented. Mobile learning is a vast field, and it has been discovered that there are numerous opportunities for research in this area that have not yet been explored in the context of engineering education.

\section{Identified gaps and future research}

This systematic review identified research gaps and research opportunities in the area of mobile collaborative learning in engineering education, and it made recommendations for future research. First and foremost, the majority of the articles 
chosen were concerned with mobile app development and agent-based applications. There has only been a small amount of research conducted on various types of web 2.0 applications for collaborative learning in engineering. In addition, collaborative learning allows for more interactions to take place. But only a few studies have been done on the topic of interaction monitoring in mobile collaborative learning in engineering education, according to the authors of the paper.

For the second time, the findings of this systematic review revealed that the pedagogy involved in engineering education has not been adequately addressed when designing engineering courses for mobile collaborative learning environments. It is possible to incorporate virtual laboratories into engineering curricula, which is a novel screening technique that can shape engineering education. Third, according to the findings of this systematic literature review, when implementing mobile collaborative learning in engineering education, two articles used a design-based research approach to do so. Finally, engineering education encompasses a wide range of disciplines such as civil engineering, chemical engineering, material engineering, and many others. However, the studies included in this review were restricted to computer engineering, electrical engineering, and electronic engineering. In order to investigate mobile collaborative learning for other engineering disciplines, there are numerous opportunities to do so.

\section{Limitations}

The scope of this review was limited to articles indexed in two databases: Web of Science and SCOPUS, with publication dates ranging from 2010 to 2020 . While it is believed that the publications in these databases will have a significant impact on the field, it is possible that they will not include the most recent research because articles published in top-ranked journals take several years to publish. However, because this study's findings and recommendations are based on peer-reviewed research, the findings may be limited to studies that established statistically significant findings. Despite the small number of papers included in this review, the selection procedure was methodical to avoid bias in the results. Future evaluations may seek to increase the number of articles reviewed by utilizing additional databases and including conference proceedings and open-access journals in order to obtain more current research trends.

\section{References}

Al-Abri, A., Jamoussi, Y., Kraiem, N., \& Al-Khanjari, Z. (2017). Comprehensive classification of collaboration approaches in e-learning. Telematics and Informatics, 34(6), 878-893.

Alnabhan, M., Abu-Al-Aish, A., \& Al-Masaeed, S. A. (2018). Collaborative and ubiquitous mobile learning system prototype. International Journal of Computer Applications in Technology, 58(4), 296.

Albers, R., Davison, C. J., \& Johnson, B. (2017). Inquiry-based learning: emirati university students choose whatsapp for collaboration. Learning and Teaching in Higher Education: Gulf Perspectives, 14(2), 37-53. 
Alioon, Y., \& Delialioğlu, Ö. (2019). The effect of authentic m-learning activities on student engagement and motivation. British Journal of Educational Technology, 50(2), 655-668.

Amara, S., Macedo, J., Bendella, F., \& Santos, A. (2016). Group formation in mobile computer supported collaborative learning contexts: A systematic literature review. Educational Technology \& Society, 19(2), 258-273.

Araújo, R. D., Brant-Ribeiro, T., Mendonça, I. E. S., Mendes, M. M., Dorça, F. A., \& Cattelan, R. G. (2017). Social and collaborative interactions for educational content enrichment in ULEs. Educational Technology and Society, 20(3), 133-144.

Asadi, S., Hussin, A. R. C., \& Dahlan, H. M. (2017). Organizational research in the field of green IT: A systematic literature review from 2007 to 2016. Telematics and Informatics, 34(7), 1191-1249.

Atawneh, S., Al-Akhras, M., Almomani, I., Liswi, A., \& Alawairdhi, M. (2020). Collaborative mobilelearning architecture based on mobile agents. Electronics, 9, 162.

Avouris, N., \& Yiannoutsou, N. (2012). A Review of mobile playful narratives for learning across physical and virtual spaces method of research. Artificial Intelligence, 18(15), 2120-2142.

Acedo, O., Sara, J. G., \& Quintana, and Carmen Cantillo Valero. (2017). Open, mobile and collaborative educational experience. case study: The European ECO project. Journal of Universal Computer Science, 23(12), 1215-1237.

Balakrishnan, B. (2015). Online computer supported collaborative learning (CSCL) for engineering students: a case study in Malaysia. Computer Applications in Engineering Education, 23(3), 352-362.

Baran, E. (2014). A review of research on mobile learning in teacher edUcation. Educational Technology and Society, 17(4), 17-32.

Barker, P. (2007). Technology in support of collaborative learning. Educational Psychology Review, 19(1), 65-83.

Bhati, A., \& Song, I. (2019). New methods for collaborative experiential learning to provide personalised formative assessment. International Journal of Emerging Technologies in Learning, 14(7), $179-195$.

Brett, P. (2011). Students' experiences and engagement with sms for learning in higher education. Innovations in Education and Teaching International, 48(2), 137-147.

Cabada, R. Z., Estrada, M. L. B., \& García, C. A. R. (2011). EDUCA: A Web 2.0 authoring tool for developing adaptive and intelligent tutoring systems using a kohonen network. Expert Systems with Applications, 38(8), 9522-9529.

Caballé, S., Xhafa, F., \& Barolli, L. (2010). Using mobile devices to support online collaborative learning. Mobile Information Systems, 6(1), 27-47.

Calvo, R., Iglesias, A., \& Castaño, L. (2017). Evaluation of accessibility barriers and learning features in $\mathrm{m}$-learning chat applications for users with disabilities. Universal Access in the Information Society, 16(3), 593-607.

Chang, H. Y., \& Ching, Y. H. (2013). Mobile computer-supported collaborative learning: a review of experimental research. British Journal of Educational Technology, 44(5), 2011-2014.

Chatti, M. A., Hamdan, N. A., \& Schaper, H. (2012). Collaboration in mobile learning seminar. In Proceedings of the Mobile Learning Computer-Supported Learning Research Group Conference (CALRG 2011). The Open University, United Kingdom.

Chee, K. N., Yahaya, N., Ibrahim, N. H., \& Hasan, M. N. (2017). Review of mobile learning trends 2010-2015: A meta-analysis. Educational Technology and Society, 20(2), 113-126.

Chen, Pearl and Hernandez; ;Dong, Jang;Anthony. 2015. "Impact of Collaborative Project-Based Learning on Self- Efficacy of Urban Minority Students in Engineering." Journal of Urban Learning Teaching and Research, 2015 Vol.11, Pp.26-39 IMPACT 11:1-35.

Chew, S. W., Ling Cheng, I., \& Kinshuk, and Nian-Shing Chen. (2018). Exploring challenges faced by different stakeholders while implementing educational technology in classrooms through expert interviews. Journal of Computers in Education, 5(2), 175-197.

Choi, S. Y., \& Kang, J. M. (2012). An Adaptive System Supporting Collaborative Learning Based on a Location-Based Social Network and Semantic User Modeling. International Journal of Distributed Sensor Networks, 8, 506810.

Chuang, Y. T. (2015). SSCLS: A smartphone-supported collaborative learning system. Telematics and Informatics, 32(3), 463-474.

Cheung, S., \& Wing and Khe Foon Hew. (2009). A review of research methodologies used in studies on mobile handheld devices in K-12 and higher education settings. Australasian Journal of Educational Technology, 25(2), 153-183. 
Chung, C. C., Dzan, W. Y., Cheng, Y. M., \& Lou, S. J. (2017). On the push-pull mobile learning of electric welding. Eurasia Journal of Mathematics, Science and Technology Education, 13(7), 3235-3260.

Connolly, T. M., Boyle, E. A., MacArthur, E., Hainey, T., \& Boyle, J. M. (2012). A systematic literature review of empirical evidence on computer games and serious games. Computers and Education, 59(2), 661-686.

Dyson, L. E., \& Frawley, J. K. (2018). A Student-generated video careers project: understanding the learning processes in and out of the classroom. International Journal of Mobile and Blended Learning, 10(4), 32-51.

Dyson, L. E., Litchfield, A., Lawrence, E., Raban, R., \& Leijdekkers, P. (2009). Advancing the M-learning research agenda for active, experiential learning: four case studies. Australasian Journal of Educational Technology, 25(2), 250-267.

Domínguez, Ernest R, Fonseca Escudero, D., Sánchez Riera, A. \& Navarro Delgado, I. (2017). Educating urban designers using augmented reality and mobile learning technologies / Formación de urbanistas usando realidad aumentada y tecnologías de aprendizaje móvil. RIED. Revista Iberoamericana de Educación a Distancia, 20(2):141.

Fakomogbon, M. A., \& Bolaji, H. O. (2017). Effects of collaborative learning styles on performance of students in a ubiquitous collaborative mobile learning environment. Contemporary Educational Technology, 8(3), 268-279.

Fu, Q. K., \& Hwang, G. J. (2018). Trends in mobile technology-supported collaborative learning: a systematic review of journal publications from 2007 to 2016. Computers and Education, 119(2017), 129-143.

Garshasbi, S., Mohammadi, Y., Graf, S., Garshasbi, S., \& Shen, J. (2019). Optimal learning group formation: a multi-objective heuristic search strategy for enhancing inter-group homogeneity and intragroup heterogeneity. Expert Systems with Applications, 118, 506-521.

Heil, C. R., Wu, J. S., Lee, J. J., \& Schmidt, T. (2016). A review of mobile language learning applications: trends, challenges, and opportunities. The EuroCALL Review, 24(2), 32.

Hinze-Hoare, V. (2007). Computer supported collaborative research. Arxiv Preprint, 1624(2003), 1-27.

Harasim, L. M., Hiltz, S. R., Teles, L., \& Turoff, M. (1995). Learning networks: A field guide to teaching and learning online. MIT press.

Hsu, Y. C., \& Ching, Y. H. (2013). Mobile computer-supported collaborative learning: A review of experimental research. British Journal of Educational Technology, 44(5), 2011-2014.

Huang, J. J. S., Yang, S. J. H., Huang, Y. M., \& Hsiao, I. Y. T. (2010). Social learning networks: build mobile learning networks based on collaborative services. Educational Technology and Society, 13(3), 78-92.

Huang, Y. M., Liao, Y. W., Huang, S. H., \& Chen, H. C. (2013). A Jigsaw-based cooperative learning approach to improve learning outcomes for mobile situated learning. Educational Technology and Society, 17(1), 128-140.

Hwang, G. J., \& Tsai, C. C. (2011). Research Trends in mobile and ubiquitous learning: a review of publications in selected journals from 2001 to 2010. British Journal of Educational Technology, 42(4), 65-70.

Hwang, G. J., \& Po Han, Wu. (2014). Applications, impacts and trends of mobile technology-enhanced learning: a review of 2008-2012 publications in selected SSCI journals. International Journal of Mobile Learning and Organisation, 8(2), 83-95.

Jain, M., Birnholtz, J., Cutrell, E., \& Balakrishnan, R. (2011). Exploring display techniques for mobile collaborative learning in developing regions. In Proceedings of the 13th international conference on human computer interaction with mobile devices and services. Stockholm: ACM Press.

Jayaweera, P. (2019). The impact model: teachers' mobile learning adoption in higher education. International Journal of Education and Development Using Information and Communication Technology, 15(4), 71-88.

Johnson, D., Johnson, R., \& Smith, K. (1998). Cooperative Learning Center Directors : Roger T Johnson And. The Annual Report of Education Psychology in Japan, 2016, 29.

Kukulska-Hulme, A., \& John;. Ettit, Linda;. Bradley, Ana A., . Carvalho, Anthony;. Herrington, David M. Kennedy, Walker, and Davidkennedy. (2011). Mature Students Using Mobile Devices in Life and Learning. International Journal of Mobile and Blended Learning, 3(1), 18-52.

Kukulska-Hulme, A. (2007). Mobile Usability in Educational Contexts : What Have We Learnt ? International Review of Research in Open and Distance Learning, IRRODL. https://doi.org/10.19173/ irrodl.v8i2.356 
Kumar, B. A., \& Chand, S. S. (2018). mobile learning: A systematic review. Education and Information Technologies, 114(11), 1-5.

Kumar, B. A., \& Mohite, P. (2018). Usability of mobile learning applications: A systematic literature review. Journal of Computers in Education, 5(1), 1-17.

Laru, J., Näykki, P., \& Järvelä, S. (2015). Four stages of research on the educational use of ubiquitous computing. IEEE Transactions on Learning Technologies, 8(1), 69-82.

Lee, H., Parsons, D., Kwon, G., Kim, J., Petrova, K., Jeong, E., \& Ryu, H. (2016). Cooperation begins: encouraging critical thinking skills through cooperative reciprocity using a mobile learning game. Computers and Education, 97, 97-115.

Lee, K. B. (2011). Developing mobile collaborative learning applications for mobile users. International Journal of Interactive Mobile Technologies, 5(4), 42-48.

Lim, G., Shelley, A., \& Heo, D. (2019). The regulation of learning and co-creation of new knowledge in mobile learning. Knowledge Management and E-Learning, 11(4), 449-484.

Shih, L. Y., Chang, Y. C., \& Chu, C. P. (2016). Novel approach to facilitating tradeoff multi-objective grouping optimization. IEEE Transactions on Learning Technologies, 9(2), 107-119.

Garcia, L., Diego, A., Tomas, D. J., Sanguino, M., Ancos, E. C., \& Gonzalez, I. F. D. V. (2016). A Debate and Decision-Making Tool for Enhanced Learning. IEEE Transactions on Learning Technologies, 9(3), 205-216.

Lu, Chris, Maiga Chang, Kinshuk, Echo Huang, and Ching Wen Chen. 2015. The Effect of Story in Mobile Educational Game.

Ma, Xiulin, Jingjing Liu, Jing Liang, and Chenyu Fan. 2020. "An Empirical Study on the Effect of Group Awareness in CSCL Environments." Interactive Learning Environments 0(0): 1-16.

MacCallum, K., Day, S., Skelton, D., \& Verhaart, M. (2017). Mobile affordances and learning theories in supporting and enhancing learning. International Journal of Mobile and Blended Learning, 9(2), 61-73.

Makewa, L. N., Kuboja, J. M., Yango, M., \& Ngussa, B. M. (2014). ICT-integration in higher education and student behavioral change: observations at university of Arusha, Tanzania. American Journal of Educational Research, 2(11A), 30-38.

Malegiannaki, I., \& Daradoumis. (2017). Analyzing the educational design, use and effect of spatial games for cultural heritage: a literature review. Computers and Education, 108, 1-10.

Manathunga, K., \& Hernández-Leo, D. (2018). Authoring and enactment of mobile pyramid-based collaborative learning activities. British Journal of Educational Technology, 49(2), 262-275.

Moher, David, Alessandro Liberati, Jennifer Tetzlaff, Douglas G. Altman, Doug Altman, Gerd Antes, David Atkins, Virginia Barbour, Nick Barrowman, Jesse A. Berlin, Jocalyn Clark, Mike Clarke, Deborah Cook, Roberto D'Amico, Jonathan J. Deeks, P. J. Devereaux, Kay Dickersin, Matthias Egger, Edzard Ernst, Peter C. Gøtzsche, Jeremy Grimshaw, Gordon Guyatt, Julian Higgins, John P. A. Ioannidis, Jos Kleijnen, Tom Lang, Nicola Magrini, David McNamee, Lorenzo Moja, Cynthia Mulrow, Maryann Napoli, Andy Oxman, Bá Pham, Drummond Rennie, Margaret Sampson, Kenneth F. Schulz, Paul G. Shekelle, David Tovey, and Peter Tugwell. 2009. "Preferred Reporting Items for Systematic Reviews and Meta-Analyses: The PRISMA Statement." PLoS Medicine $6(7)$

Moore, M. G. (1989). Editorial: Three types of interaction. American Journal of Distance Education, $3(2), 1-7$.

Muhisn, Z. A., Aljasim, M. A., Omar, M., \& Muhisn, S. A. (2019). The impact of socialization on collaborative learning method in E-learning Management System (ELMS). International Journal of Emerging Technologies in Learning, 14(20), 137-148.

Neto, Pedro and Bill Williams. 2013. "More Activity, Less Lectures: A Technology Stewardship Approach Applied to Undergraduate Engineering Learning." Proceedings - 2013 1st International Conference of the Portuguese Society for Engineering Education, CISPEE 2013.

Osman, H. M., Singh, M. M., Shariff, A. R. M., Bakar, A. A., \& Plasencia, M. S. (2018). Enhanced analytical hierarchy process for U-Learning with Near Field Communication (NFC) technology. International Journal of Advanced Computer Science and Applications, 9(12), 281-290.

Patten, B., Sánchez, I. A., \& Tangney, B. (2006). Designingcollaborative, constructionist and contextual applications for handheld devices. Computers \& Education,46, 294-308. Elsevier. https:// doi.org/10.1016/j.compedu.2005.11.011

Pimmer, C., Mateescu, M., \& Gröhbiel, U. (2016). Mobile and ubiquitous learning in higher education settings. A systematic review of empirical studies. Computers in Human Behavior, 63, 490-501. 
Ramírez-Donoso, L., Rojas-Riethmuller, J. S., Pérez-Sanagustín, M., Neyem, A., \& Alario-Hoyos, C. (2017). MyMOOCSpace: A cloud-based mobile system to support effective collaboration in higher education online courses. Computer Applications in Engineering Education, 25(6), 910-926.

Reychav, I., Dunaway, M., \& Kobayashi, M. (2015). Understanding mobile technology-fit behaviors outside the classroom. Computers and Education, 87, 142-150.

Rodriguez-Andina, J. J., Gomes, L., \& Bogosyan, S. (2010). Current trends in industrial electronics education. IEEE Transactions on Industrial Electronics, 57(10), 3245-3252.

Ryu, H., \& Parsons, D. (2012). Risky business or sharing the load?-Social flow in collaborative mobile learning. Computers and Education, 58(2), 707-720.

Spikol, D. (2008). Playing and learning across locations: Indentifying factors for the design of collaborative mobile learning. Reports from MSI 111.

Scott, K., \& Benlamri, R. (2010). Context-aware services for smart learning spaces. IEEE Transactions on Learning Technologies, 3(3), 214-227.

Snoussi, T., Belkacem, H. B., Radwan, A. F., \& Gaidi, M. (2020). Social media for learning: Perceptions and behaviors. Periodicals of Engineering and Natural Sciences, 8(4), 2195-2207.

Son, J., Kim, J. D., Na, H. S., \& Baik, D. K. (2016). A social learning management system supporting feedback for incorrect answers based on social network services. Educational Technology and Society, 19(2), 245-257.

Sun, G., Cui, T., Yong, J., Shen, J., \& Chen, S. (2018). MLaaS: A cloud-based system for delivering adaptive micro learning in mobile MOOC learning. IEEE Transactions on Services Computing, 11(2), 292-305.

Sun, G., \& Shen, J. (2014). Facilitating social collaboration in mobile cloud-based learning: a teamworkas a service (TaaS) Approach. IEEE Transactions on Learning Technologies, 7(3), 207-220.

Sun, G., \& Shen, J. (2016). Towards organizing smart collaboration and enhancing teamwork performance: A GA-supported system oriented to mobile learning through cloud-based online course. International Journal of Machine Learning and Cybernetics, 7(3), 391-409.

Swid, A., Hsu, H.-Y., \& Wang, S.-K. (2018). Mobile Learning application to facilitate ubiquitous collaborative learning: An organizational behavior course. Journal of Higher Education Theory and Practice. https://doi.org/10.33423/jhetp.v18i4.570

Tawfik, M., Sancristobal, E., Martin, S., Diaz, G., Peire, J., \& Castro, M. (2013). Expanding the boundaries of the classroom: Implementation of remote laboratories for industrial electronics disciplines. IEEE Industrial Electronics Magazine, 7(1), 41-49.

Temdee, P. (2014). Ubiquitous learning environment: smart learning platform with multi-agent architecture. Wireless Personal Communications, 76(3), 627-641.

Temdee, P. (2016). Agent-based modeling of collaborative interaction in ubiquitous learning environment using local dynamic behavior. Artificial Life and Robotics, 21(2), 215-220.

Tricco, A. C., Lillie, E., Zarin, W., O’Brien, K., Colquhoun, H., Kastner, M., Levac, D., Ng, C., Sharpe, J. P., Wilson, K., Kenny, M., Warren, R., Wilson, C., Stelfox, H. T., \& Straus, S. E. (2016). A scoping review on the conduct and reporting of scoping reviews. BMC Medical Research Methodology, 16(1), 1-11.

Troussas, C., Krouska, A., \& Sgouropoulou, C. (2020). Collaboration and fuzzy-modeled personalization for mobile game-based learning in higher education. Computers and Education, 144(2019), 103698.

Tuckman, B. W. (1965). Developmental sequence in small groups. Psychological Bulletin, 63(6), 384-399.

Wu, W. H., Yen Chun Jim, Wu., Chen, C. Y., Kao, H. Y., Lin, C. H., \& Huang, S. H. (2012). Review of trends from mobile learning studies: A meta-analysis. Computers and Education, 59(2), 817-827.

Xia, L., \& Zhong, B. (2018). A systematic review on teaching and learning robotics content knowledge in K-12. Computers and Education, 127(122), 267-282.

Yafie, E., Samah, N. A., Mohamed, H., \& Haqqi, Y. A. (2020). Collaborative mobile seamless learning $(\mathrm{Cmsl})$ Based on android apps to improving critical thinking in higher education in the PostCovid-19 Era. Journal of Advanced Research in Dynamical and Control Systems, 12(7), 428-441.

Yannibelli, V., \& Amandi, A. (2012). A deterministic crowding evolutionary algorithm to form learning teams in a collaborative learning context. Expert Systems with Applications, 39(10), 8584-8592.

Zheng, L. (2015). A systematic literature review of design-based research from 2004 to 2013. Journal of Computers in Education, 2(4), 399-420.

Zhou, X., Chen, J., Bo, Wu., \& Jin, Q. (2014). Discovery of action patterns and user correlations in task-oriented processesfor goal-driven learning recommendation. IEEE Transactions on Learning Technologies, 7(3), 231-245. 
Zhu, G., Xing, W., \& Popov, V. (2019). Uncovering the sequential patterns in transformative and nontransformative discourse during collaborative inquiry learning. Internet and Higher Education, 41(February), 51-61.

Zydney, J. M., \& Warner, Z. (2016). Mobile apps for science learning: Review of research. Computers and Education, 94, 1-17.

Publisher's Note Springer Nature remains neutral with regard to jurisdictional claims in published maps and institutional affiliations.

Anuradha Peramunugamage is a Programmer cum Systems Analyst at the Faculty of Engineering at the University of Moratuwa in Sri Lanka. She has over a decade of professional experience in information systems, learning management systems, and educational technologies. She earned a B.Sc. (Hons) in Information Technology from the Sri Lanka Institute of Information Technology in 2004, a M.Sc. in Information Management from the same institute in 2007, and reading for an MPhil in Educational Technology from the University Of Colombo School Of Computing in Sri Lanka. She is currently pursuing a PhD in Educational Technology at The Open University of Sri Lanka. She is a member of the IEEE Young Professionals, Education Society, and Women in Engineering, the EDEN - European Distance and E-Learning Network, and the Network of Academics and Professionals (NAP), the Organization for Women in Science for the Developing World (OWSD), the Association for Learning Technology (ALT), the Sri Lanka Association for the Advancement of Science (SLAAS), and the Sri Lanka Association for Young Scientists (SLAYS). She is particularly interested in educational technology, blended learning, e-learning, mobile learning, Open Educational Resources (OER), and engineering education. She has authored research articles that have been published in peer-reviewed journals and conference proceedings. 